\title{
Design and Development of Real-Time E-Voting System with High Security Features
}

\author{
Amit Mishra ${ }^{\text {a }}$, Abdullahi Ofujeh Ahmad ${ }^{\mathrm{b}}$ \\ ${ }^{a}$ Baze University, Abuja, Nigeria \\ ${ }^{b}$ Nigerian Nile Turkish University, Abuja, Nigeria
}

Received: 17 December 2018; Accepted: 15 February 2019; Published: 08 May 2019

\begin{abstract}
In this day and age of developing cutting edge innovations, the traditional voting technique can be changed to a more up to date and powerful approach termed as electronic voting system. The electronic voting system gives a helpful, simple and proficient approach to cast a ballot eliminating the shortcomings of traditional approach. The point of this research work is to exhibit an electronic voting system (E-Voting) to be connected to organization constituent body. A software application was developed utilizing web API's and the concept of Dynamic systems development method (DSDM) used with object-oriented methodology for the development of the application.
\end{abstract}

Index Terms: Electronic voting systems, Real Time, Nigeria electoral system, Manual voting systems, voting system design.

(C) 2019 Published by MECS Publisher. Selection and/or peer review under responsibility of the Research Association of Modern Education and Computer Science.

\section{Introduction}

Electronic voting alludes to the utilization of PCs or modernized voting equipment to cast polls in an election. Now and then, this term is utilized all the more particularly to allude to voting that happens over the Web. Electronic systems can be utilized to enlist voters, tally votes, and record cast a ballot [1]. Higher institution is required to have free and fair elections for a popularity based of the understudy's affiliation. Elections empower the people to pick their representatives to express their preferences for how they will be administered. Thus, the respectability and precision of the election procedure are principal to the trustworthiness of the democracy itself. Applications are basic bit of the cutting-edge world. As a matter of fact, society and culture must be in order to address the difficulties of the information age. Application is a power that has changed various behaviour by

* Corresponding author.

E-mail address: i.amitmishra@gmail.com,ofujeh@gmail.com 
which individual's lives. In perspective of such fields as instruction, the travel industry, drug, business, design, building, finance home and law, in the past at least two decades the impact of use has been huge. Today, various new innovative progressions are building up the automated security and sensible exchange including electronic voting system which is turning into an outstanding pattern. The essential goal of e-Voting is to give voters an incredible situation so individuals can cast their votes with minimum cost and endeavours. Electronic voting refers to the use of computers or computerized voting equipment to cast ballots in an election. Sometimes, this term is used more specifically to refer to voting that takes place over the Internet. Electronic systems can be used to register voters, tally ballots, and record votes [2]

\section{Related Work}

Over the previous years, society and numerous days by day parts of life have been changed technologically. In [3] proposed the utilization of Remote Internet Voting, with a view to improve voter comfort, increment voter certainty and voter turnout. In the review, authors recommended remote survey site electronic casting a ballot as the best advance forward as it gives better voter comfort, and yet, does not trade off security. In [4], the authors Avi Rubin (2001) survey the safety efforts required for remote web-based casting a ballot framework by concentrating on two situations where voters cast their polls over the Internet - the 2000 Arizona Democratic Primary and the University of Virginia Student Council Elections. The author guarantees that a protected casting a ballot system should completely fulfil four noteworthy prerequisites: verification, accessibility, classification and uprightness.

A broad review of e-voting a ballot innovation has been given in "E-Voting Security Study" [5]. This study shows a review on the projects in academic and commercial area. It additionally recognizes the different dangers, potential wellsprings of assault and conceivable techniques for assault in such e-voting systems. Security targets and significant necessities of E-voting have been obviously indicated in this work.

[6] Presents a framework for secure electronic casting a ballot which does not depend on network connections between polling places and the vote-counting server. They assemble the framework on a separated (or, all the more precisely, a discontinuously associated) condition, which carries on well without system availability.

[7] See a promising future for electronic voting, in spite of its issues today" (under a couple of conditions). They advocate utilizing the techniques as of now being used which result in the most reduced normal quantities of "uncounted, plain, and ruined votes," like in-region optical filtering. Their report even proposes a structure for another voting system with a decentralized, modular plan. [8] Gives a rundown of proposals for "nonexclusive voting criteria" which recommends that a voting system ought to be so difficult to mess with thus impervious to disappointment that no business system is probably going to ever meet the necessities, and building up a reasonable custom system would be very troublesome and restrictively costly. $[9,10]$ concocted the "Mercuri strategy" for electronic voting. A basic part of this strategy is fundamentally the same as the Caltech/MIT proposition: a voting machine must deliver intelligible printed copy paper results, which can be confirmed by the voter before the vote is thrown, and physically described later if essential. Her reasoning and Neumann's are fundamentally the same as; truth be told, they've composed papers together regarding the matter.

A broad review of e-voting innovation has been given in "e-Voting Security Study" [11]. It gives an overview of ongoing scholastic and business extends in the territory, notwithstanding the zone's noticeable scholastics' close to home perspectives and declarations with respect to the issues. It distinguishes dangers, potential wellsprings of assault and conceivable strategies for assault in such voting systems. It likewise recognizes security goals and prerequisites of an electronic voting system. [12] Presents a system for secure electronic voting which does not depend on relentless network connections between polling places and the vote-counting server. They assemble the system on a disconnected (or, all the more precisely, an intermittently connected) condition, which carries on well without network availability. "Security Criteria for Electronic Voting" [13] considers some fundamental criteria for privacy, honesty, accessibility, unwavering quality, and affirmation for computer systems engaged in electronic voting. After an evaluation of the feasibility of those 
criteria, it infers that, operationally, a large number of the criteria are naturally unsatisfiable with any important affirmation.

\section{A. Advantage of utilizing E-voting System}

The electronic voting systems are expected both to decrease mistakes and to accelerate the counting procedure. Preferences of Electronic Voting system over the ordinary poll paper/voting booth system are It decreases to a great expanse the quantity of paper used so saving a large number of trees making the process eco-friendly.

1. It declines to an extraordinary breadth the amount of paper utilized so sparing countless of trees making the procedure eco-accommodating.

2. It expels the likelihood of invalid and unverifiable votes which, much of the time, are the underlying drivers of dispute and election appeal.

3. It makes the strategy of tallying the votes considerably quicker than the traditional system.

4. It limited the expense of printing just about zero.

5. To improve and provide fast way of conducting election irrespective of the population.

6. Generation of voter's access through sms sending to the voters at the voting poll unit.

7. More accurate results as human error is excluded.

8. To provide accurate record of candidate information and reliable database.

\section{Research Methodology}

The framework used of structuring, planning and controlling the process in developing information system in software engineering is known as Software development methodology or System development methodology. (www.itinfo.am, 2014) [14].

The events completed at each step of a software development project is describes by a framework Software development life cycle (SLDC). (slideshare.net, 2014) [15].

\section{A. Requirement Elicitation and Analysis}

The classification of the problems to be undertook by the system in order for the system to solve a problem is focused by system requirement elicitation stage.

The procedure used for eliciting the requirement in this research is an amalgamation of research, brainstorming and observation.

\section{B. Functional Requirements}

Functional requirements are defined by the function or component required of an application. Mostly, the expression of functional requirements is in the format "system compulsory action". The format chosen to present the functional requirements is the following:

ID: The identification number of the requirement.

Description: The requirement.

Explanation: An explanation of the requirement especially needed for those which are complex. 
Table 1. Functional Requirements the e-Voting Model

\begin{tabular}{|c|c|c|}
\hline ID & Description & Explanation \\
\hline FR-01 & $\begin{array}{l}\text { Inclusive interactive platform is required from the } \\
\text { application }\end{array}$ & $\begin{array}{l}\text { An environment in which user can make use of } \\
\text { application easily must be provided. }\end{array}$ \\
\hline FR-02 & The application must restrict duplicate voting & $\begin{array}{l}\text { The application will not allow the voters to vote for one } \\
\text { post more than once. }\end{array}$ \\
\hline FR-03 & $\begin{array}{l}\text { The application must generate and delivery voters } \\
\text { access code. }\end{array}$ & $\begin{array}{l}\text { The application must be able to grant voters access code } \\
\text { immediately. }\end{array}$ \\
\hline FR-04 & The application must filter ip address & $\begin{array}{l}\text { The application will on grant access to computer that the } \\
\text { address is store in the main server. }\end{array}$ \\
\hline FR-05 & $\begin{array}{l}\text { The application must always give summary of the } \\
\text { election activities. }\end{array}$ & $\begin{array}{l}\text { The application will continually give the summary of } \\
\text { number of votes cast so far, number of voters yet to vote } \\
\text { and number of voters currently voting (Online). }\end{array}$ \\
\hline FR-06 & $\begin{array}{l}\text { The application must cumulative the number of } \\
\text { votes casted accurately. }\end{array}$ & $\begin{array}{l}\text { The results of the poll must be counted accurately based } \\
\text { on post and candidate }\end{array}$ \\
\hline
\end{tabular}

\section{Non-Functional Requirements}

The interpretation of not what application will do is finished by non-functional requirement, yet how the framework will do it, for instance, system structure limitations, execution requirements, application outer interface requirements, and programming quality characteristics.

Underneath, the most critical classes of the non-functional requirements are introduced dependent on their significance: ease of use, modifiability / extensibility, convenience, adaptability, dependability, security, execution, add up to cost:

The system's related non-functional requirements are given below:

Table 2. Non-Functional Requirements

\begin{tabular}{lll}
\hline ID & Description & Explanation \\
\hline NFR-01 & $\begin{array}{l}\text { The user interface must be easy enough } \\
\text { for anyone, all screens should have a } \\
\text { similar style. }\end{array}$ & $\begin{array}{l}\text { The buttons, menus and designs ought to be the equivalent in every one } \\
\text { of the screens of the application. The clients will execute particular } \\
\text { activities unquestionably. They will locate similar choices and menus in } \\
\text { each screen, while clicking the route buttons. }\end{array}$ \\
NFR-02 & $\begin{array}{l}\text { The application will be able to run on } \\
\text { all web browsers on various devices. }\end{array}$ & $\begin{array}{l}\text { The application will be created to keep running on all internet browsers } \\
\text { in PCs, Android gadgets, for example, mobiles, tablets or whatever } \\
\text { other gadget that uses the Android working framework. } \\
\text { The application ought to give every one of its activities quick. The } \\
\text { client must not sit tight for any activity for quite a while. On the off } \\
\text { chance that something needs time to be executed, at that point a turning } \\
\text { loader will be shown until the finish of the task. } \\
\text { The application must be structured so that any developer can add new } \\
\text { tasks and highlights to the source code. }\end{array}$ \\
& $\begin{array}{l}\text { The application will have fast response } \\
\text { time. }\end{array}$ & $\begin{array}{l}\text { The application must be designed to be } \\
\text { able to accept new operations and } \\
\text { features. }\end{array}$
\end{tabular}

\section{System Design}

The design phase of a software system to build an answer for the issue as characterized in the requirement elicitation process. Design stage sets up a general architecture by dividing the software into parts, the connections and conditions between such segments is then settled.

Unified Modelling Language (UML) which is utilized in object-oriented system analysis and design will be 
used to demonstrate the different segments of the framework and also their connections and conditions. UML diagram, for example, entity relational diagram and dataflow diagram drawn and to demonstrate the system functions.

\section{E-Voting System Entity Relational Diagram}

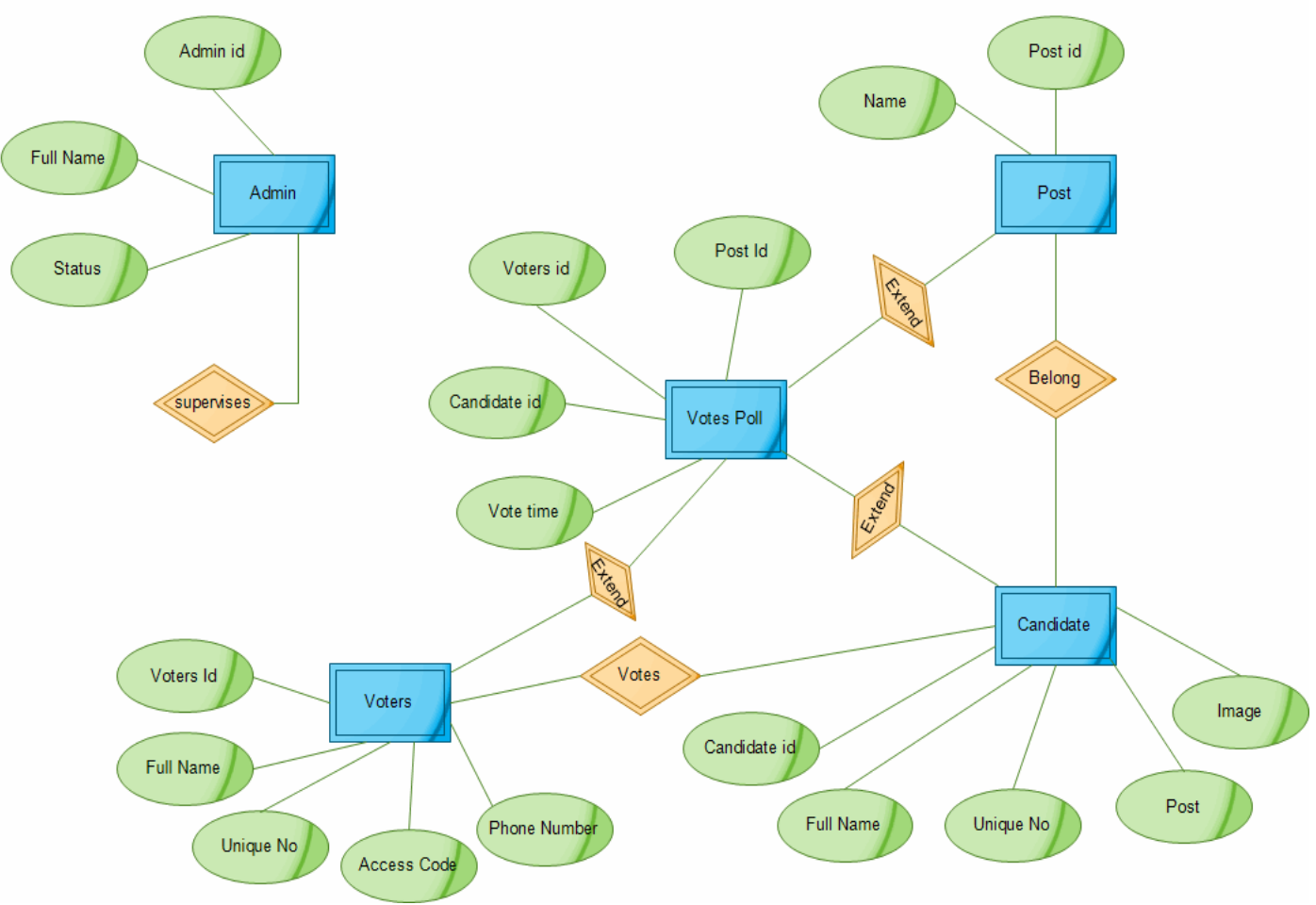

Fig.1. E-voting System entity Relational Diagram

\section{E-Voting System Data Flow Model Diagram}

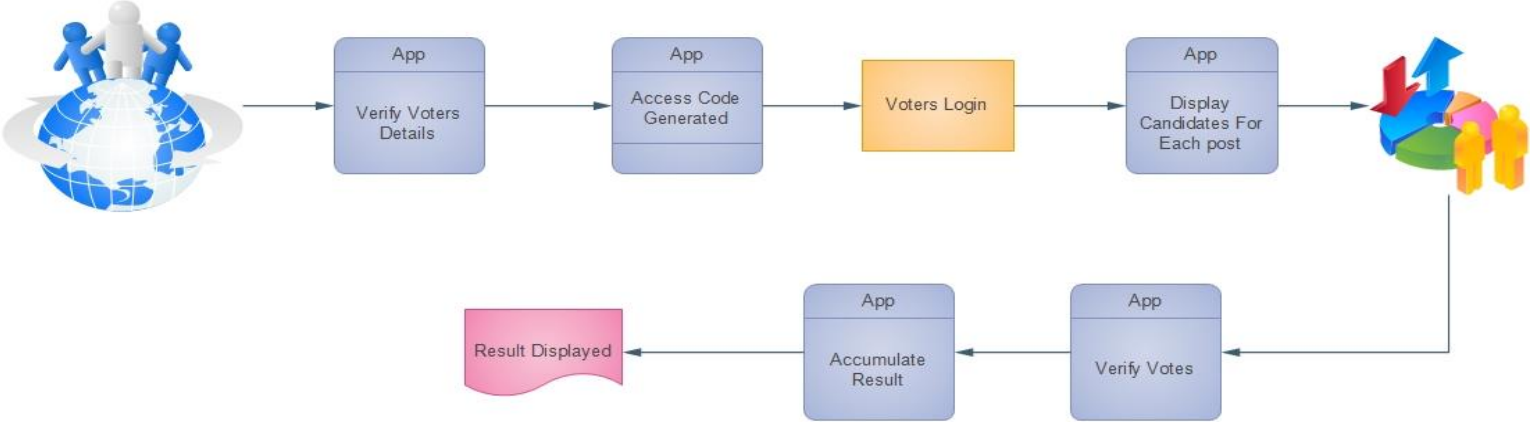

Fig.2. E-voting System Data Flow Model Diagram 


\section{Implementation}

1. Firstly, all voters will have to be digitally captured.

2. All interested aspirants will have to be registered for the respective offices

3. On the election date, all the students will be verified if really, he/she is being capture, before going to cast their vote.

4. After the verification, access code of random number will be sent to the voters' phone number to have access to the system to cast their votes.

5. No Voter can vote for a specific post more than one time.

6. During the election, summary of the election will be projected, this which includes:

- Total number of registered Student

- Total number of people registered to vote

- Total number of expected to vote

- Total number of people remaining to vote

- The current voters online

7. At the end of the election, the result will be display instantly to every one for transparency, and credibility.

\section{An Overview of the E-Voting System}

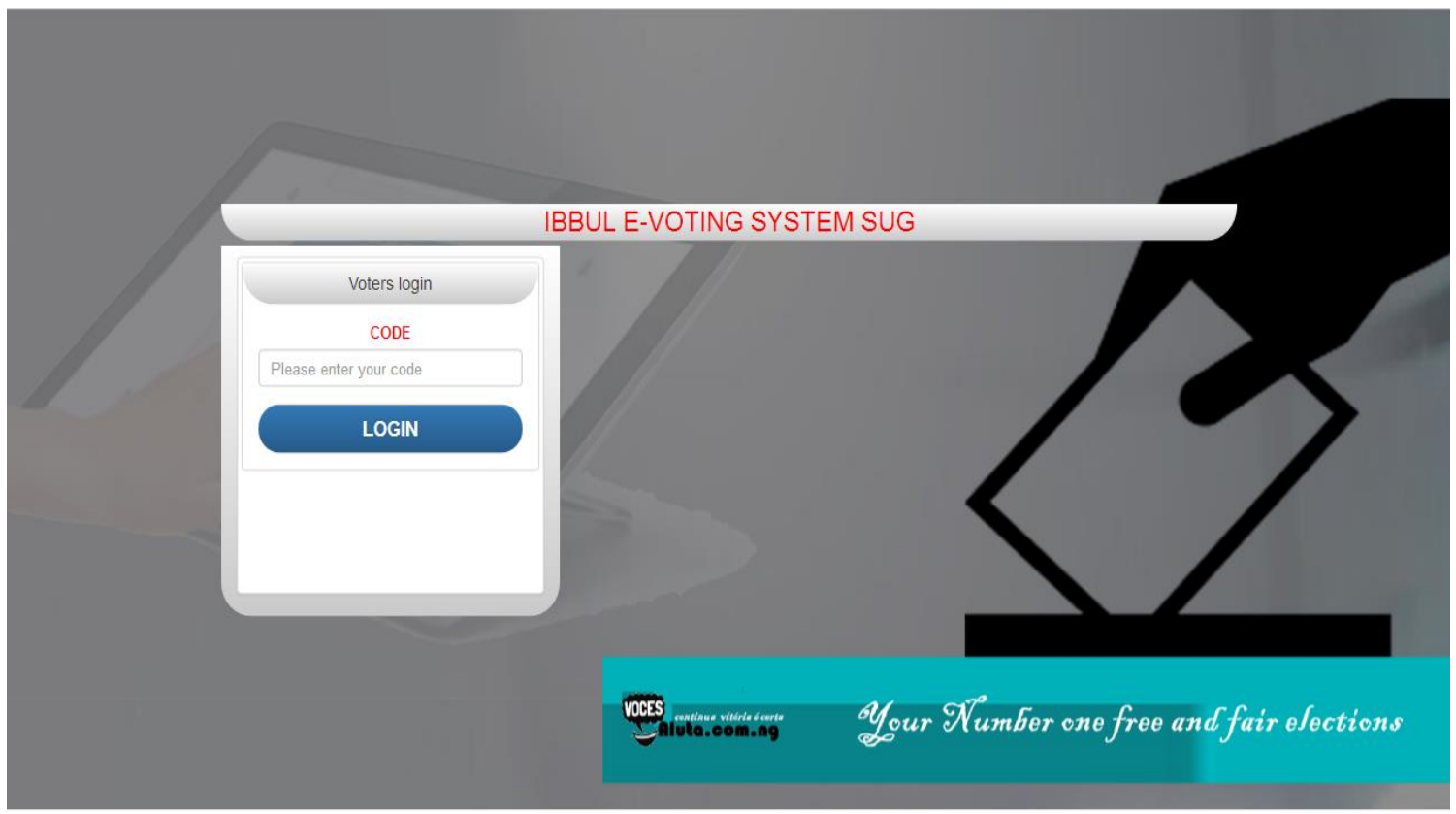

Fig.3. Administrator Login Page 


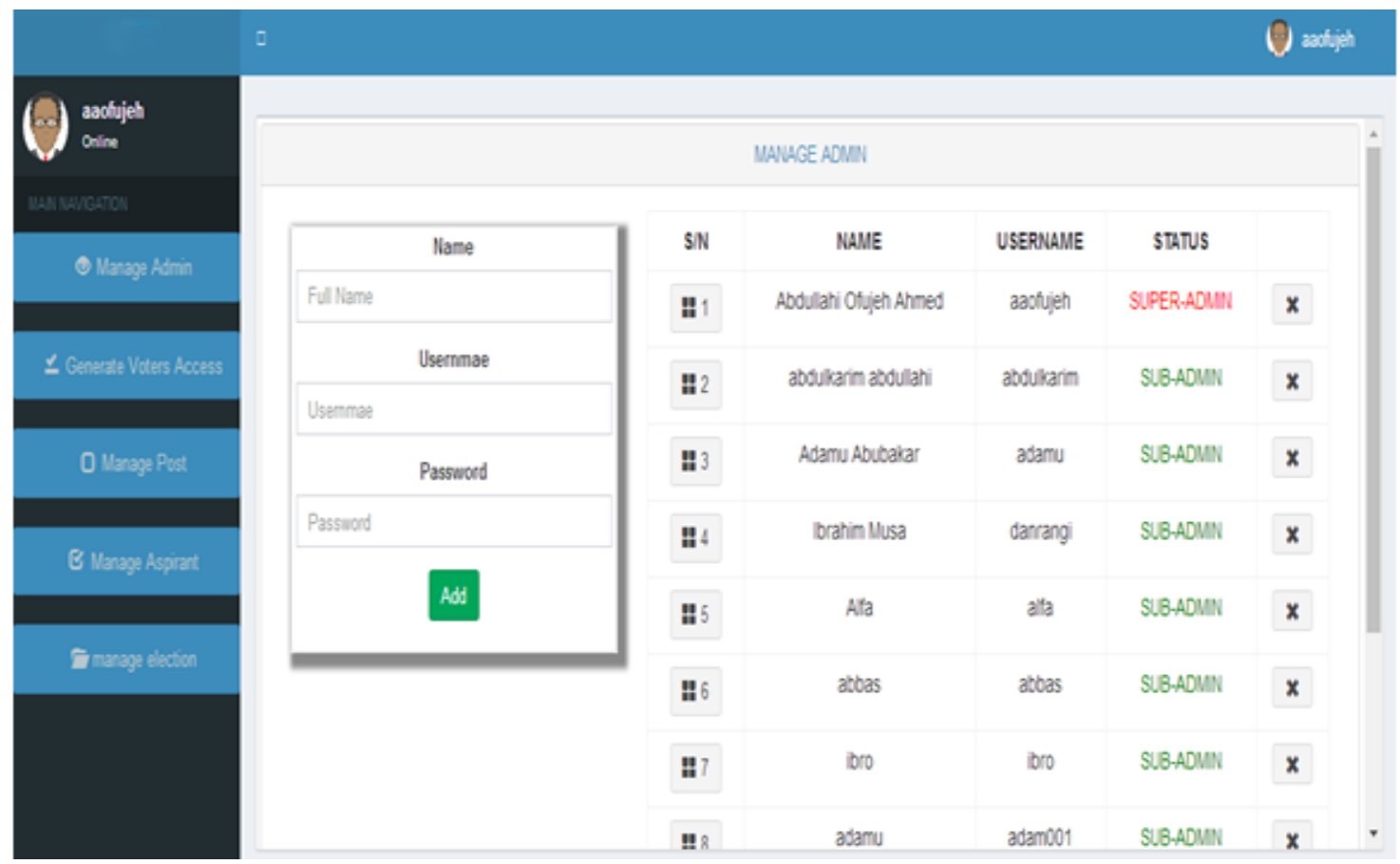

Fig.4. Manage Administrator Module

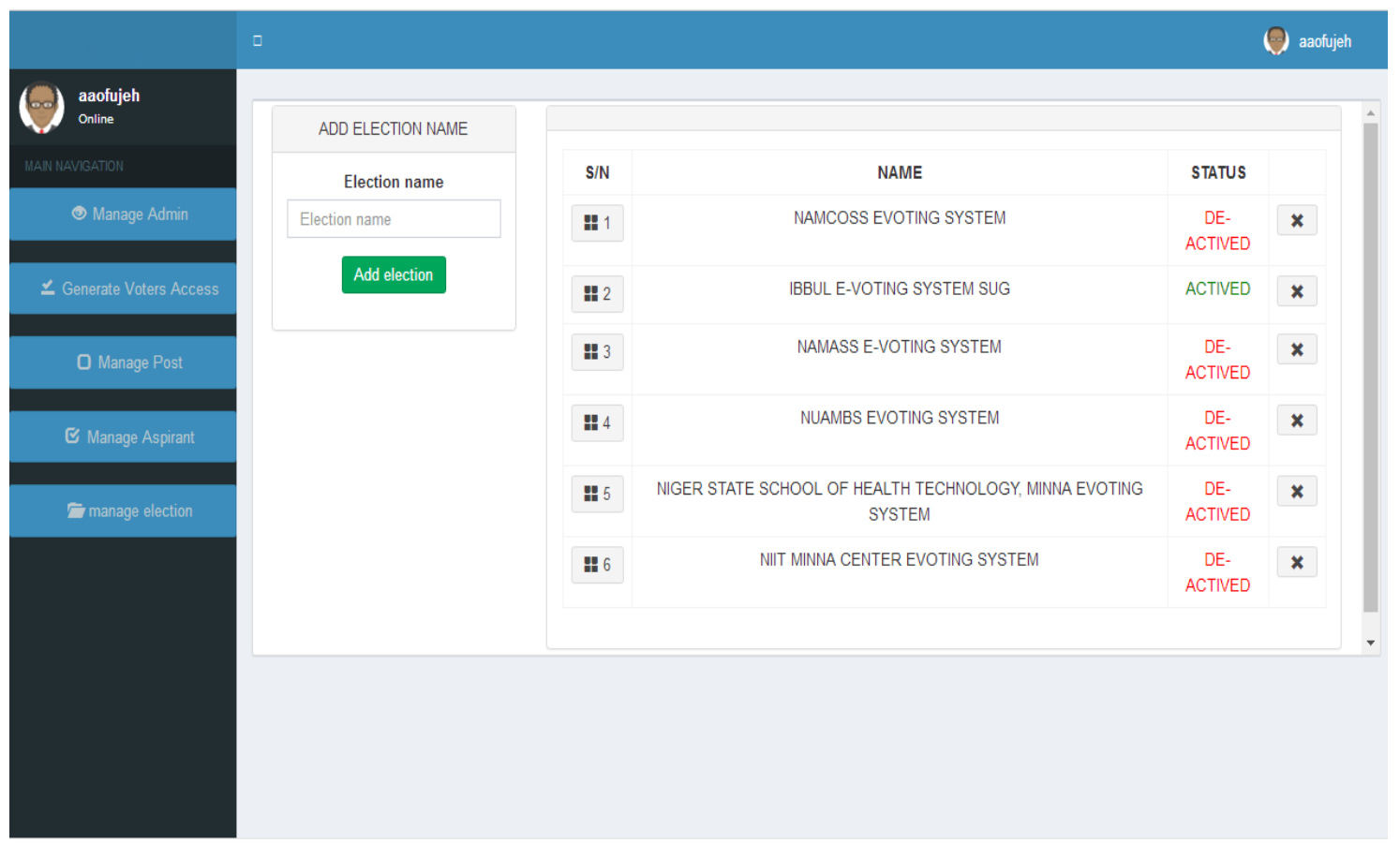

Fig.5. Manage Election Module 


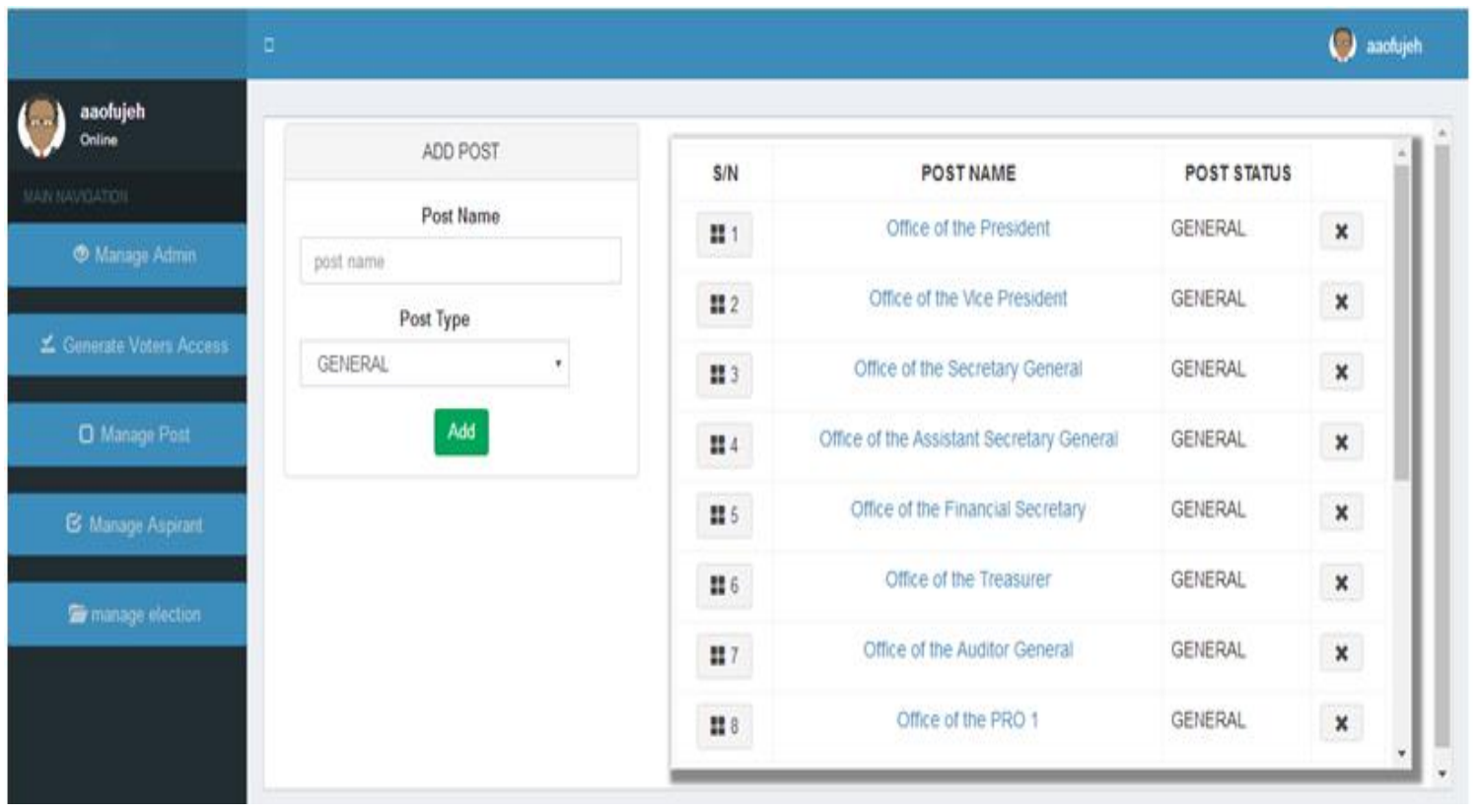

Fig.6. Manage Posts Module

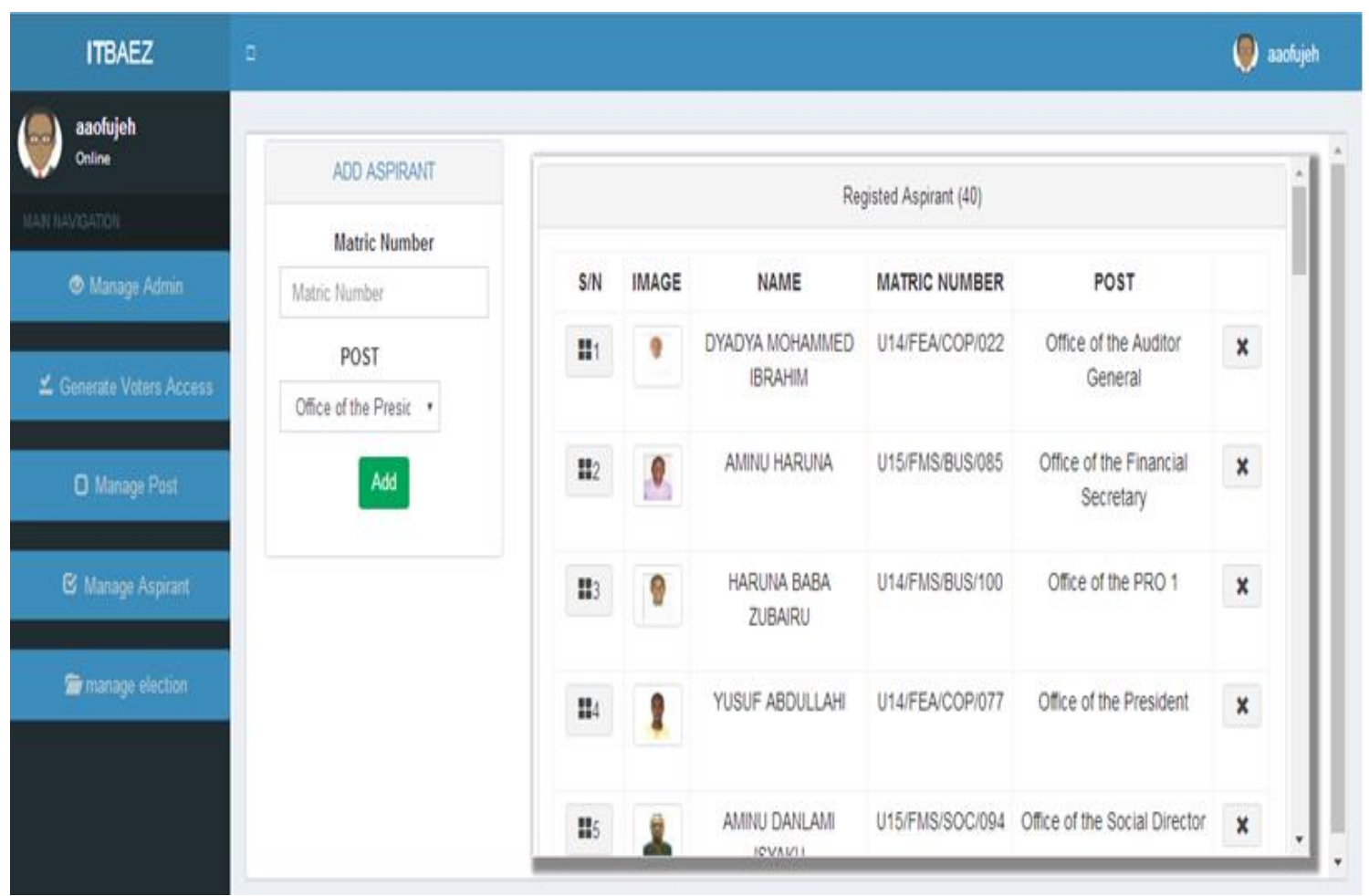

Fig.7. Manage Candidate's Module 


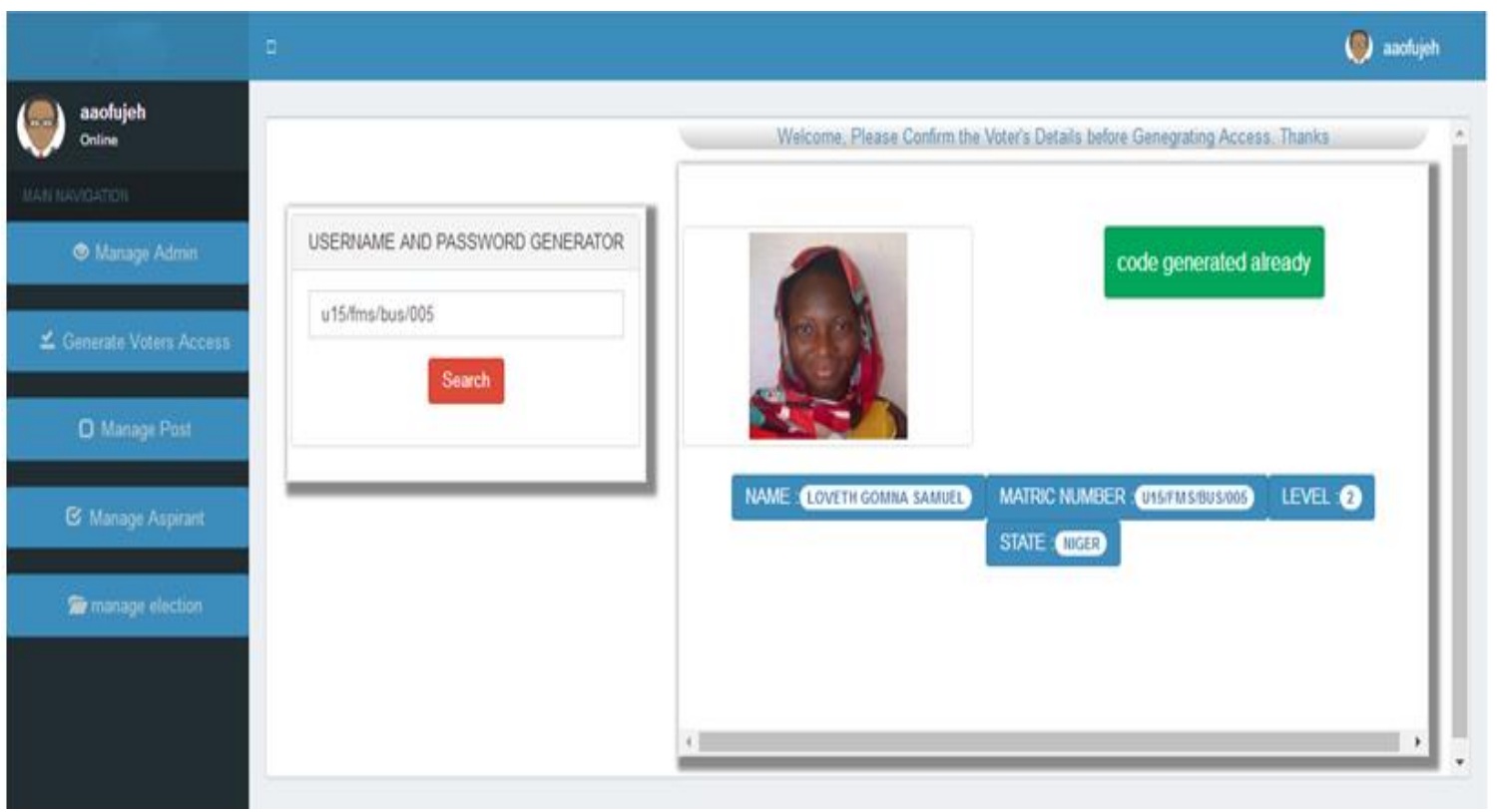

Fig.8. Voters Access Code Generation I

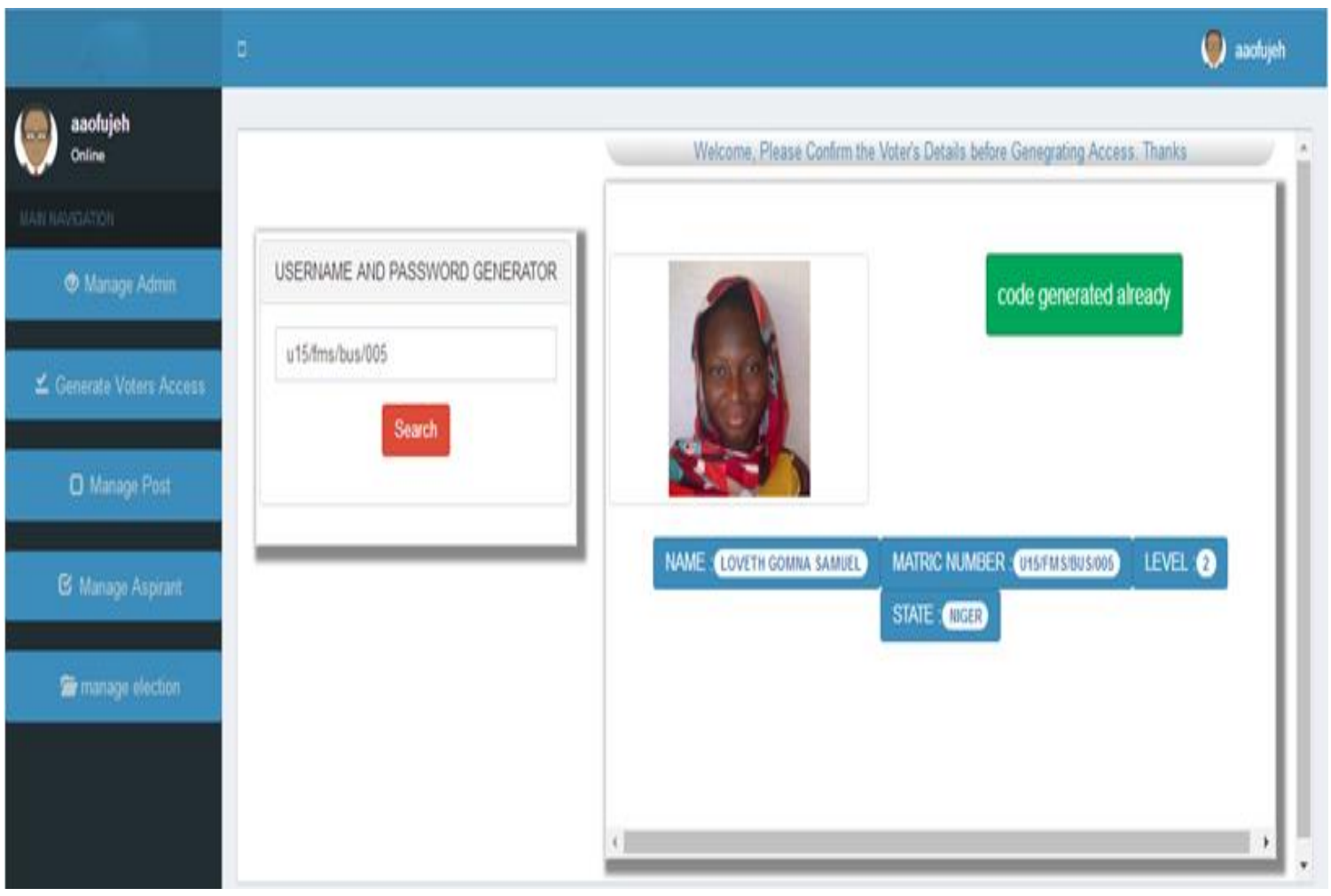

Fig.9. Voters Access Code Generation II 


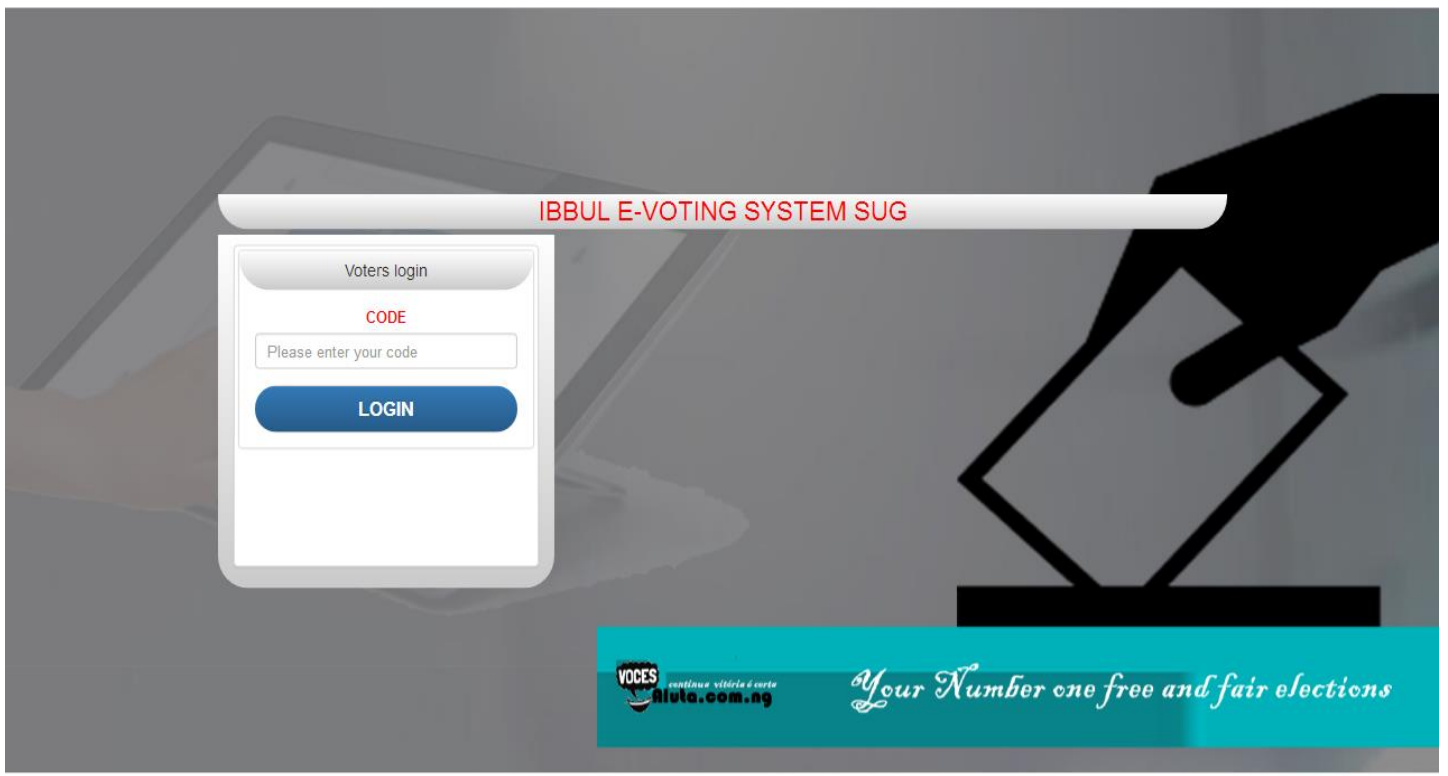

Fig.10. Voters Login Page

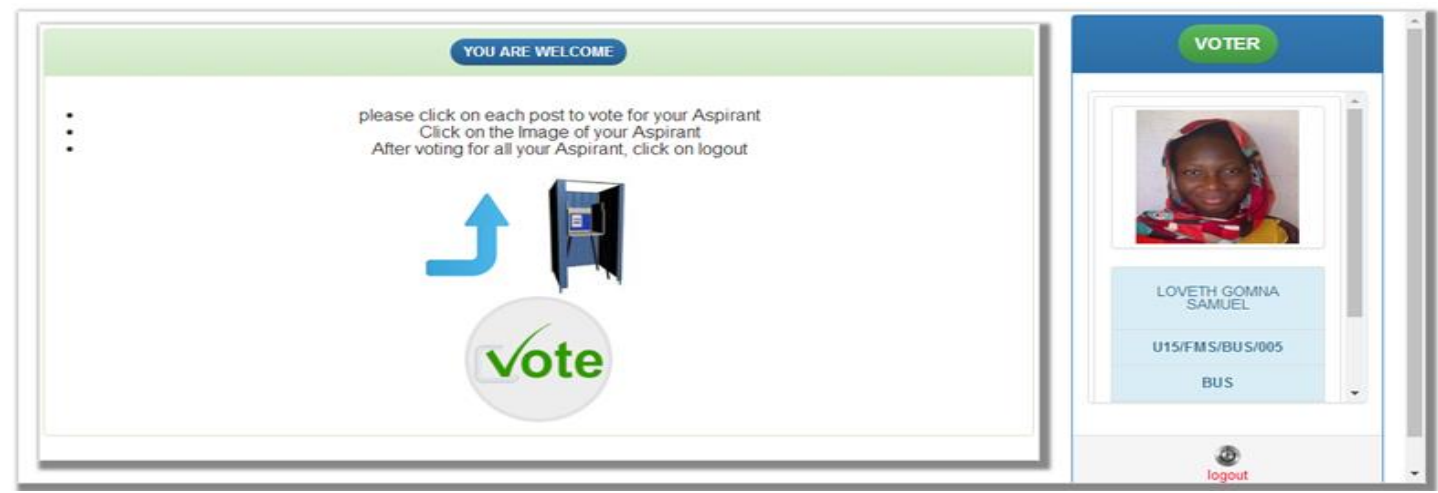

Fig.11. Voters Welcome Page

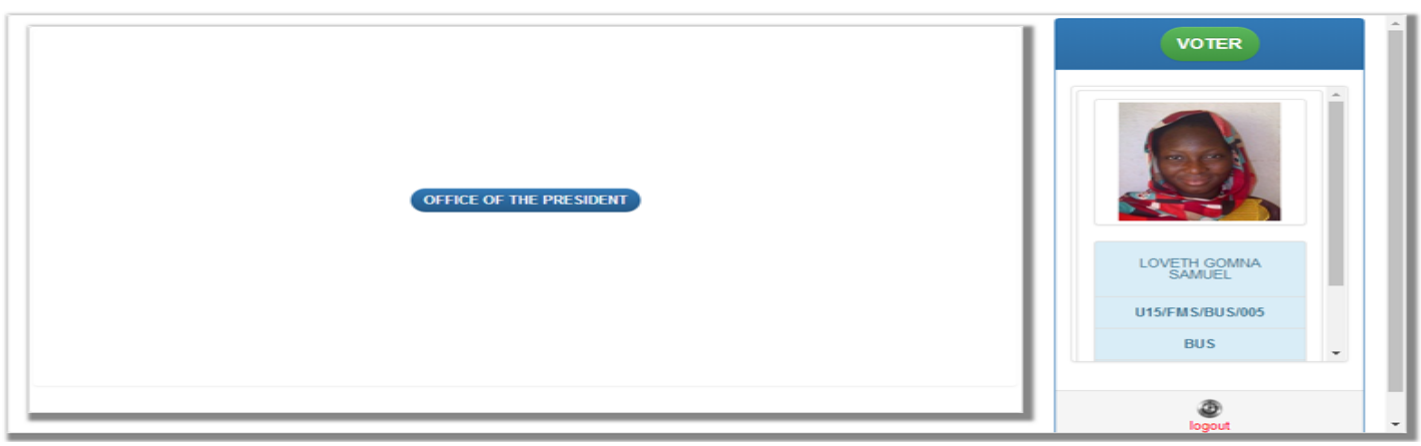

Fig.12. Voters Voting Process I 


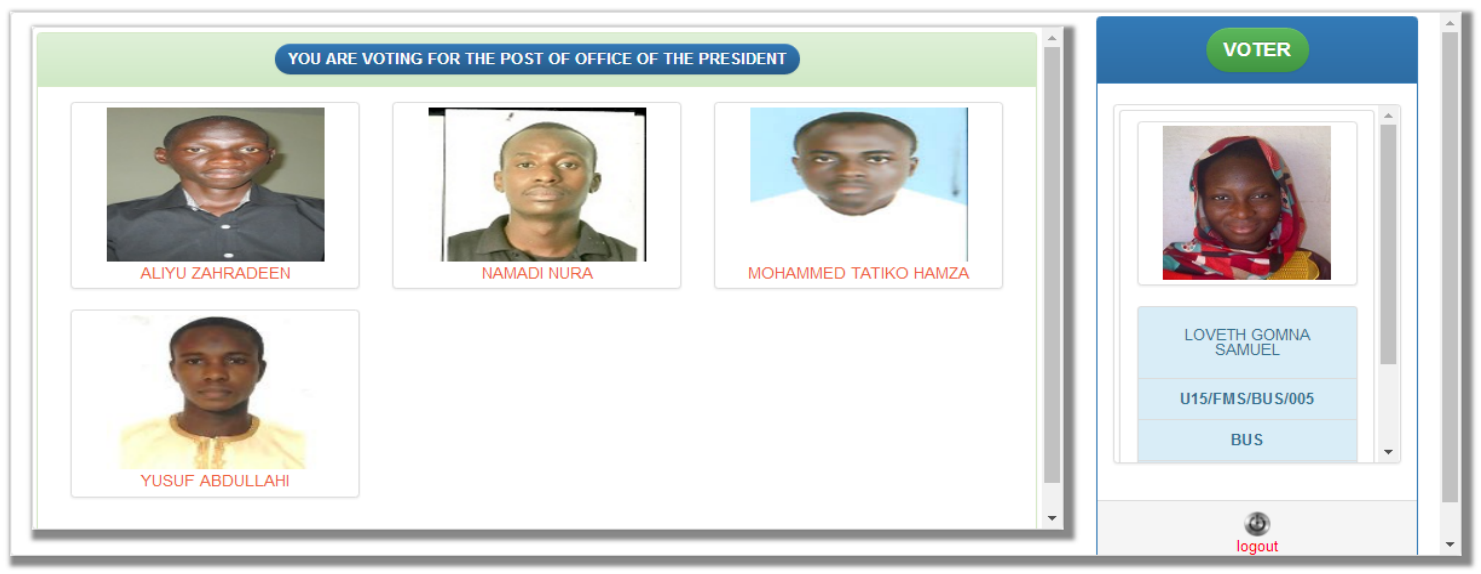

Fig.13. Voters Voting Process II

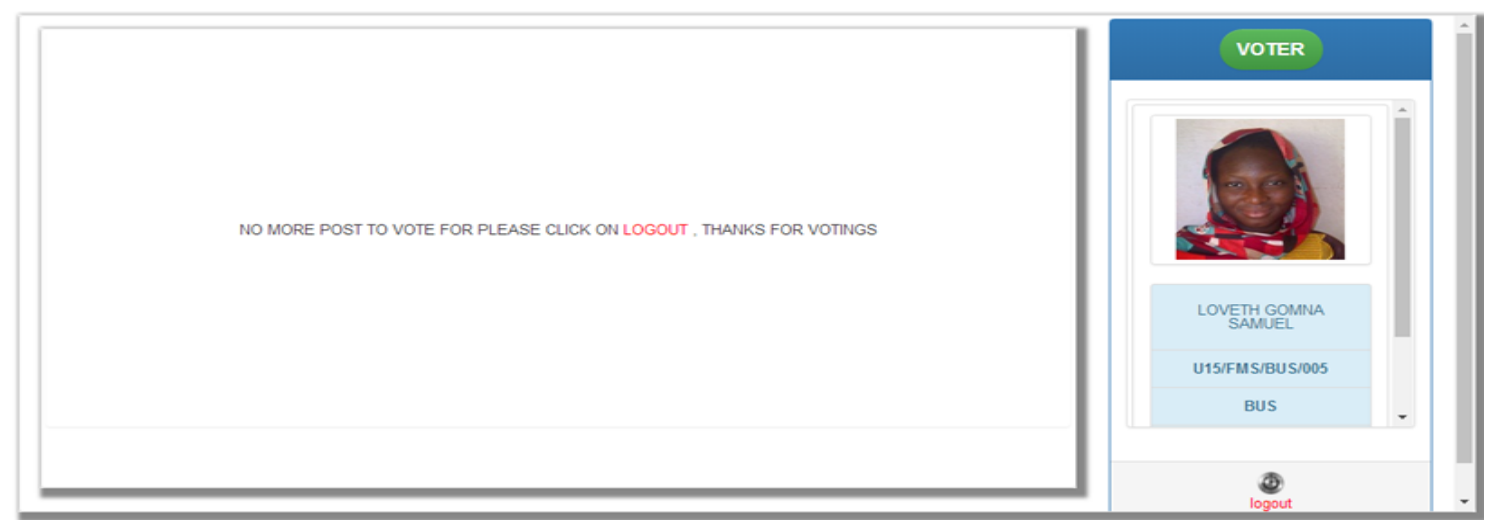

Fig.14. Voters Voting Process III

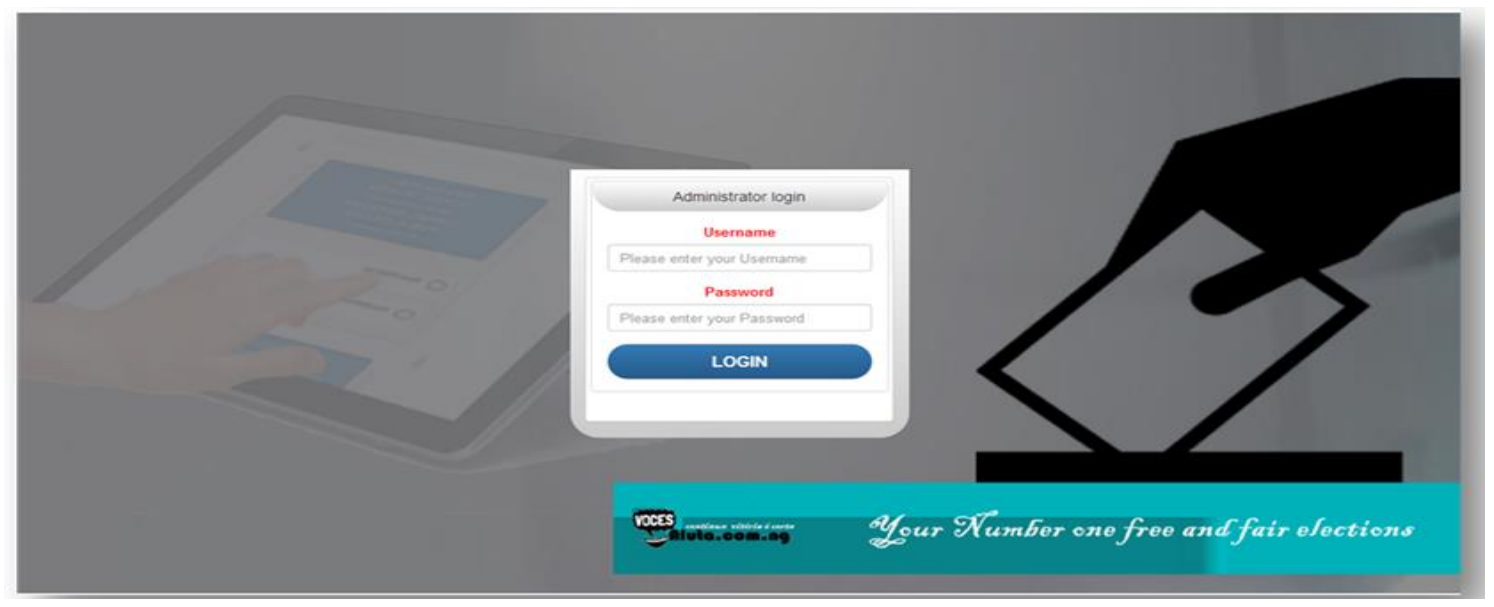

Fig.15. Admin Login to Access Election Result 


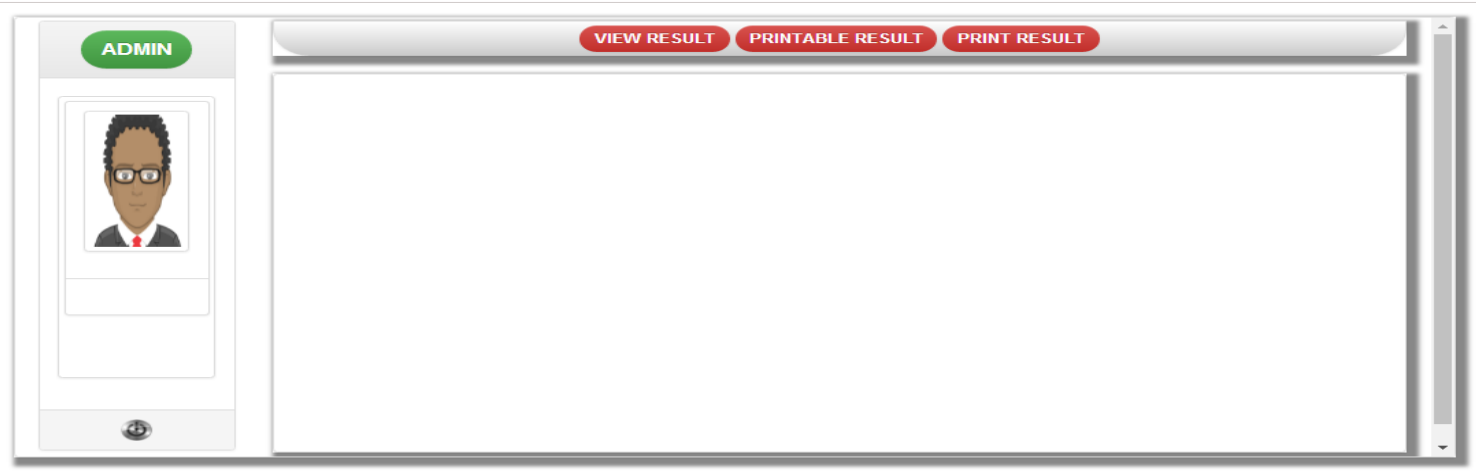

Fig.16. Result Dashboard Module

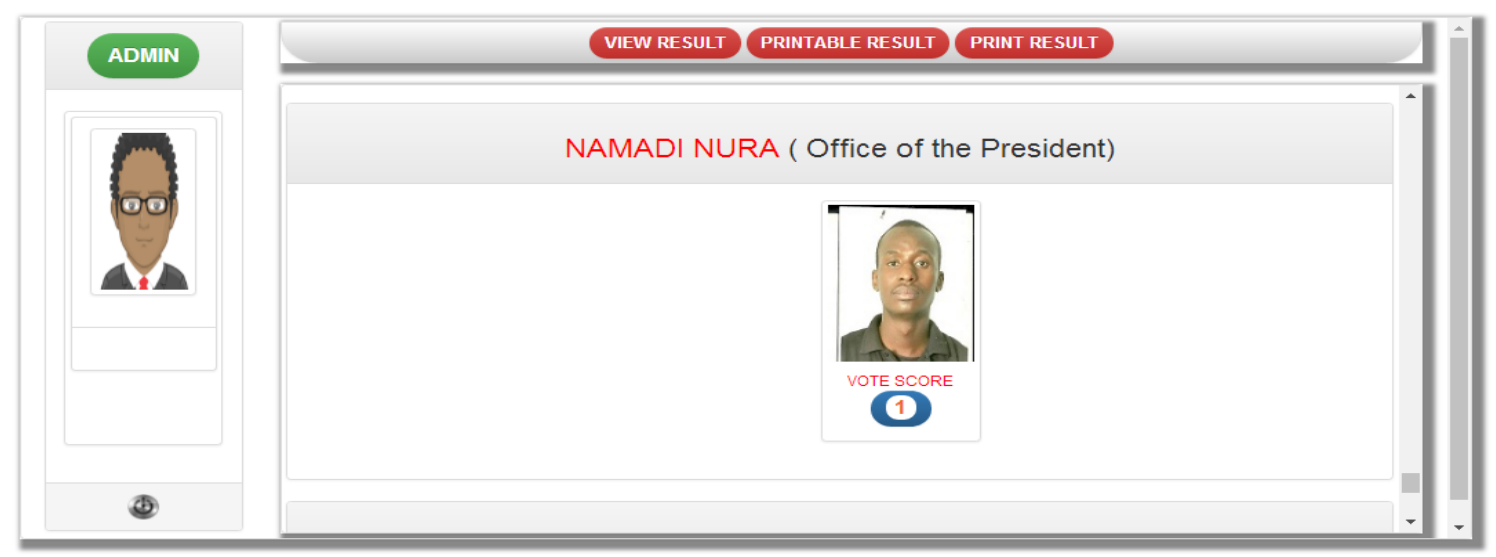

Fig.17. Result Display

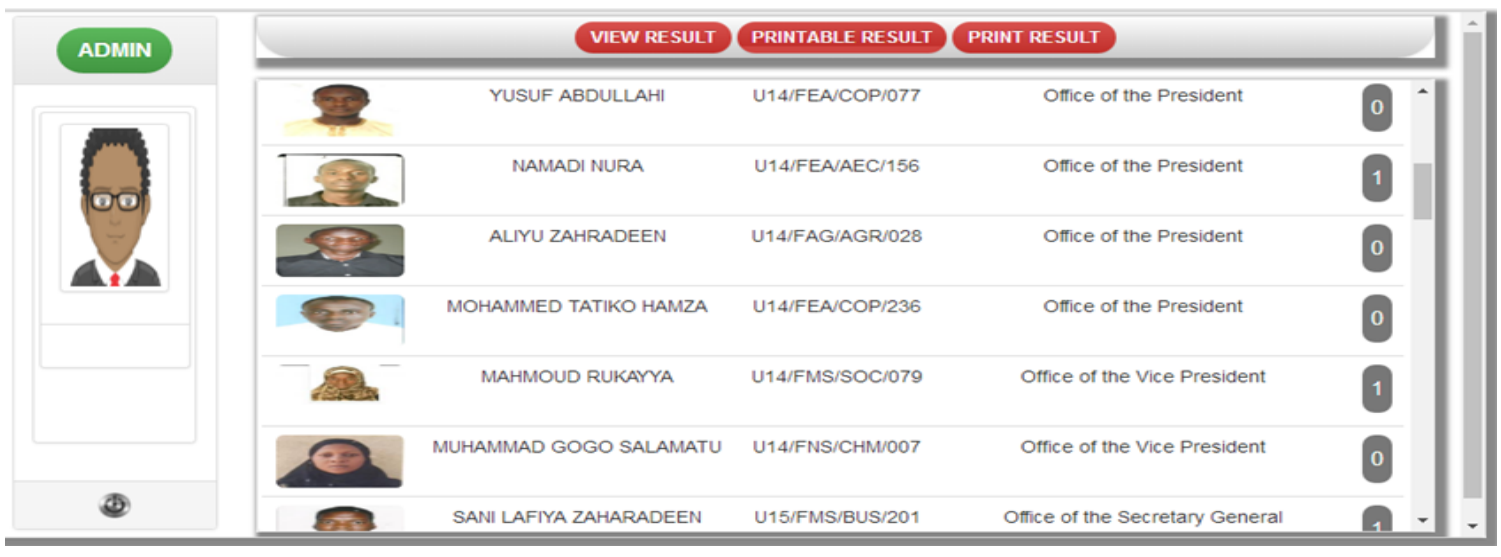

Fig.18. Result Display in Printable Manner 


\section{Conclusion}

In this research work, we set out to build up a savvy answer for handle the intermittent issues of election conduct by using electronic voting system for election conducting purpose. This research featured the advantages of electronic voting system in election conduct.

This research thusly, utilizing data system standard of Software Development Life Cycle (SDLC) model, Dynamic systems development method (DSDM) and Object-Oriented Analysis and Design, set out to build up a utility electronic voting system which when conveyed on web browsers of a gadget, and conceivably empower voting effectively done. Following the Dynamic systems development method (DSDM) stages, Unified Modelling Language (UML) diagram, entity relational diagram and dataflow diagram of every part and the whole system was planned.

Brackets was the development environment of decision for the implementation phase of this research, as it gives an achieve set of free modules for the development of web application, the most imperative module which is the web application interface for Brackets. The application created was tested utilizing one of the web testing devices called Selenium.

\section{Reference}

[1] "Electronic Voting," Encyclopedia of Computers and Computer History, prepared by Lorrie Faith Cranor and edited by Raul Rojas, published by Fitzroy Dearborn, 2001.

[2] "Electronic Voting," Encyclopedia of Computers and Computer History, prepared by Lorrie Faith Cranor and edited by Raul Rojas, published by Fitzroy Dearborn, 2001.

[3] Rossler T.G (2011),"E-voting: A survey and Introduction", Available at http://wiki.agoraciudadana.org/images/5/56/An\%2BIntroduction\%2Bto\%2BElectronic\%2BVoting\%2B Schemes.pdf Retrieved on 15th June 2012.

[4] Avi Rubin (2001),"Security Considerations for Remote Electronic Voting over the Internet", AT\&T Labs Research Florham Park, NJ. Available at http://avirubin.com/evoting.security.html, (date accessed 7th July, 2012).

[5] E-Voting Security Study,” E-Democracy Consultation, U. K. Cabinet Office, http://www.edemocracy.gov.uk/library/papers/study.pdf.

[6] "Secure Voting Using Disconnected, Distributed Polling Devices," David Clausen, Daryl Puryear and Adrian Rodriguez, Department of Computer Science, Stanford University.

[7] A Preliminary Assessment of the Reliability of Existing Voting Equipment," The Caltech-MIT Voting Technology Project, March 30, 2001 (revised). Available at http://www.vote.caltech.edu/Reports/index.html)

[8] "Security Criteria for Electronic Voting," Peter Neumann, presented at the 16th National Computer Security Conference Baltimore, Maryland, September 20-23, 1993. Available at http://www.csl.sri.com/users/neumann/ncs93.html

[9] A Better Ballot Box?" Rebecca Mercuri, IEEE Spectrum, Volume 39, Number 10, October 2002.

[10] Electronic Voting,” Rebecca Mercuri. http://www.notablesoftware.com/evote.html

[11] "E-Voting Security Study," E-Democracy Consultation, U. K. Cabinet Office, http://www.edemocracy.gov.uk/library/papers/study.pdf.

[12] "Security Criteria for Electronic Voting," Peter G. Neumann, 16th National Computer Security Conference, Baltimore, Maryland, September 20-23, 1993.

[13] "Security Considerations for Remote Electronic Voting," Aviel D. Rubin, Communications of the ACM, Vol. 45, No. 12, December 2002.

[14] www.itinfo.am, 2014 
[15] 3slideshare.net, 2014

\section{Authors' Profiles}

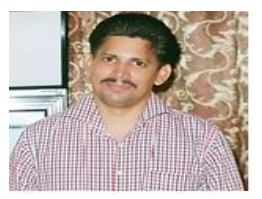

Amit Mishra (PhD): E-mail: i.amitmishra@gmail.com, Tel: + 2347081924140

Dr. Amit Mishra is an Assistant Professor in the Department of Computer Science, at Baze University, Abuja, Nigeria. His current research interests include: Software Engineering, Reverse Engineering, Software maintenance, web development, mobile app. $\mathrm{He}$ has been publishing in the above-mentioned fields in various national and international journals. He is also Microsoft Certified professional in Win2K and Exchange Server.

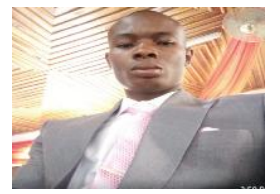

Abdullahi Ofujeh Ahmed: E-mail: ofujeh@gmail.com, Tel: +2348132537768

Abdullahi Ofujeh Ahmed is graduate student of computer science, Nile university Abuja, Nigeria. His current area of interest includes: web development, mobile app development, desktop app development and Software engineering. He also has key knowledge of programming languages such as java, python, $\mathrm{C}, \mathrm{C}^{++}$and database management such as Oracle, Mysql.

How to cite this paper: Amit Mishra, Abdullahi Ofujeh Ahmad,"Design and Development of Real-Time EVoting System with High Security Features", International Journal of Education and Management Engineering(IJEME), Vol.9, No.3, pp.37-50, 2019.DOI: 10.5815/ijeme.2019.03.04 